\title{
Perimammary uniportal vats fissureless right anterior segmentectomy for lung metastasectomy: a case report
}

\author{
Norberto Santana-Rodriguez ${ }^{1,2} \wedge$, Raid Alhayaza ${ }^{2} \wedge$, Abdullah AlShammari $^{3} \wedge$, Rami Mohammad Alhayaza $^{2} \wedge$, \\ Ahmed Ahmed $^{1} \wedge$, Omniyah Alashgar ${ }^{\wedge}$, Diego González-Rivas ${ }^{4}$ \\ ${ }^{1}$ Thoracic Surgery \& Lung Transplant, Lung Health Centre, Organ Transplant Centre of Excellence (OTCoE), King Faisal Specialist Hospital \& \\ Research Centre, Riyadh, KSA; ${ }^{2}$ College of Medicine, Department of Surgery, Alfaisal University, Riyadh, KSA; ${ }^{3}$ Department of Thoracic Surgery, \\ Royal Brompton Hospital, London, UK; ${ }^{4}$ Department of Thoracic Surgery, Shanghai Pulmonary Hospital, Shanghai, China \\ Contributions: (I) Conception and design: N Santana-Rodriguez; (II) Administrative support: N Santana-Rodriguez, A AlShammari, A Ahmed; (III) \\ Provision of study materials or patients: N Santana-Rodriguez, R Alhayaza, A Ahmed, O Alashgar; (IV) Collection and assembly of data: R Alhayaza, \\ RM Alhayaza; (V) Data analysis and interpretation: N Santana-Rodriguez, R Alhayaza, A AlShammari, RM Alhayaza, A Ahmed; (VI) Manuscript \\ writing: All authors; (VII) Final approval of manuscript: All authors. \\ Correspondence to: Norberto Santana-Rodriguez, MD, PhD, FEBTS. Thoracic Surgery \& Lung Transplant, Lung Health Centre, Organ Transplant \\ Centre of Excellence (OTCoE), King Faisal Specialist Hospital \& Research Centre, Riyadh 11211, KSA. Email: norbesanrod@kfshrc.edu.sa.
}

\begin{abstract}
Secondary lung cancer is frequently witnessed in practice. Surgical resection is considered an essential approach in managing pulmonary metastases, with open or video-assisted thoracoscopic surgery (VATS) lobectomy typically preferred for centrally located metastasis. On the other hand, uniportal VATS anatomical segmentectomy provides an excellent lung parenchyma sparing technique to prevent the lobectomy, but it is challenging and demands strong skills in VATS. Therefore, we present a novel approach for uniportal VATS segmentectomy based on a vertical and curved utility incision performed in the perimammary fold of a 58-year-old female with a known case of colorectal cancer presented with a solitary lung metastasis located in the right anterior segment. The patient underwent, for the first time, a successful right perimammary uniportal VATS fissureless anterior segmentectomy. She experienced low postoperative pain, being the average postoperative pain (EVA scale) \pm SD $(0.466 \pm 0.9)$, and was discharged on the second postoperative day. Free margin was achieved and no recurrence has been observed within the last 20 months of follow-up. The patient is highly satisfied with the long-term cosmetic result due to a less-visible scar. In conclusion, the perimammary uniportal approach provides, low pain, short length hospital stay and an excellent cosmetic outcome. Further studies are required to prove the benefits of the perimammary approach.
\end{abstract}

Keywords: Perimammary; uniportal video-assisted thoracoscopic surgery (uniportal VATS); segmentectomy; anterior segmentectomy; case report

Received: 02 October 2021; Accepted: 29 November 2021; Published online: 15 December 2021.

doi: 10.21037 /jovs-21-39

View this article at: https://dx.doi.org/10.21037/jovs-21-39

\section{Introduction}

Secondary lung cancer is frequently witnessed in practice, regardless of the primary source. It is estimated that more than half of patients with primary colorectal cancer (CRC) will have metastatic recurrence after the resection of the primary tumor (1), most commonly in the liver or lung (2). In fact, a majority of the metastatic lung nodules faced by thoracic surgeons are associated with CRC $(3,4)$.

^ ORCID: Norberto Santana-Rodriguez, 0000-0003-3524-5991; Raid Alhayaza, 0000-0002-8335-3471; Abdullah AlShammari, 0000-0002-48892605; Rami Mohammad Alhayaza, 0000-0002-9872-5434; Ahmed Ahmed, 0000-0003-0322-2592; Omniyah Alashgar, 0000-0001-8503-6341. 


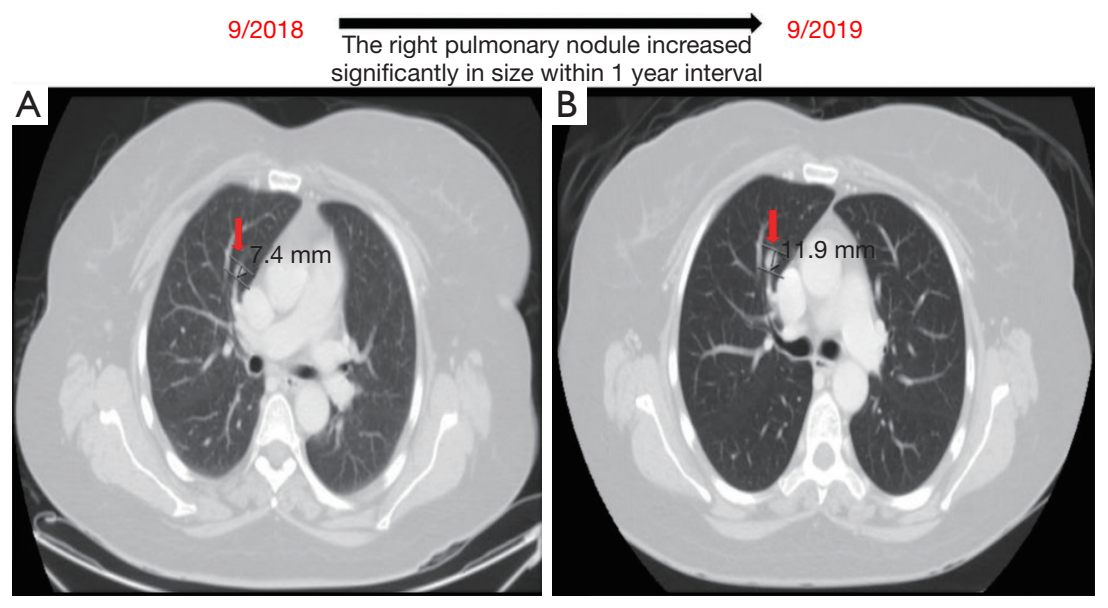

Figure 1 A pre-operative CT scan of the case patient's thoracic cavity showing a right pulmonary nodule (A) increasing significantly in size over the period of 1 year (B). Red arrows show the tumor location. CT, computed tomography.

Metastatic lung nodules are resected through various modalities, although open surgery has been the most common approach, it results in a longer hospital stay and more peri-operative complications. Video-assisted thoracoscopic surgery (VATS) is replacing the conventional thoracotomy when feasible (5). Typically, the lung wedge is the most common resection performed (6) in peripheral lung metastasis, while segmentectomy and lobectomy (with the latter slightly favoured) are indicated in centrally located metastases $(7,8)$. The VATS approach differs in centers due to the lack of a standardized technique and most surgeon still perform a multiportal approach (5).

Despite the historic preference among surgeons for multiportal VATS, the past decade has seen thoracic surgeons increasingly recognise and accept uniportal VATS $(9,10)$ due to reduced postoperative pain, fewer alterations in post-operative pulmonary function and a minimal immunological response compared to the classical approach. Furthermore, uniportal VATS provides increased exposure of the hilum and the pleural cavity $(7,11-13)$, which may be beneficial for diagnostic and therapeutic purposes of various intrathoracic conditions (13). However, small lung nodules are not easily palpated through the single incision to be resected (14).

Uniportal VATS anatomical segmentectomies are technically challenging and strong skills in VATS are required, but this approach represents an excellent lung parenchyma sparing technique for centrally located metastasis in experienced hands providing a fast patients recovery to continue with systemic treatments, if needed (15). Herein, we present a novel perimammary uniportal approach for an anatomical right anterior segmentectomy (S3) in a female patient with a centrally located CRC lung metastasis in accordance with the CARE reporting checklist (available at https://jovs.amegroups.com/article/ view/10.21037/jovs-21-39/rc) (16).

\section{Case presentation}

A 58-year-old female known case of a T3N2M0 CRC located at $12 \mathrm{~cm}$ from the anal verge, diagnosed in September 2018, underwent neoadjuvant chemo-radiation followed by laparoscopic low anterior resection with primary anastomosis in January 2019. Afterwards, the patient had 8 cycles of chemotherapy and finished the course in August 2019. The patient has no history of smoking. The initial computed tomography (CT) of the chest showed an $8 \mathrm{~mm}$ nodule in the right $\mathrm{S} 3$ with interval progression from 7.4 to $11.9 \mathrm{~mm}$ within 1 year follow-up, which is worrisome for lung metastasis (Figures 1,2). A PET scan showed FDG-avid right upper lobe lung nodule measuring $1.2 \mathrm{~cm}$ with SUV max of 9.1 without mediastinal lymphadenopathy involvement or the presence of distant metastasis (Figure 3). The bronchoscopy was negative.

The surgery was conducted under general anesthesia and, with right lung isolation, the patient underwent a perimammary uniportal VATS fissure less right upper lobe S3 segmentectomy (Figure 4). A $3 \mathrm{~cm}$ vertical and curved utility incision was performed in the right perimammary fold (Figure 5). The subcutaneous tissue was flipped up and the serratus anterior muscle fibres were split to the level of the 5 th intercostal space, where the pleural cavity was entered 


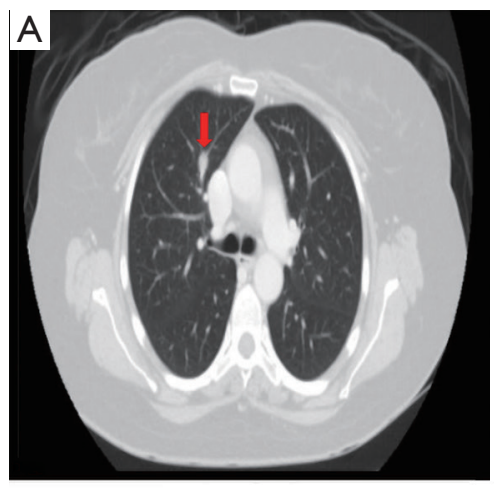

Axial

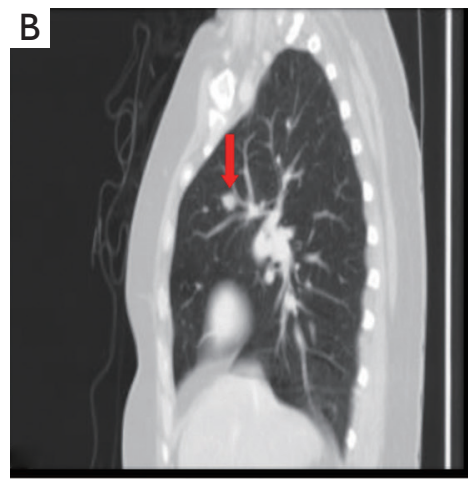

Sagittal

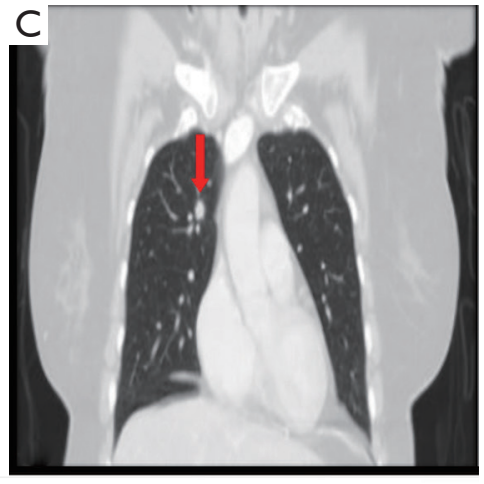

Coronal

Figure 2 Pre-operative CT scan of the case patient's thoracic cavity showing the lung metastasis in the right S3, viewed in the (A) axial, (B) sagittal and (C) coronal planes. Red arrows show the tumor location. CT, computed tomography.
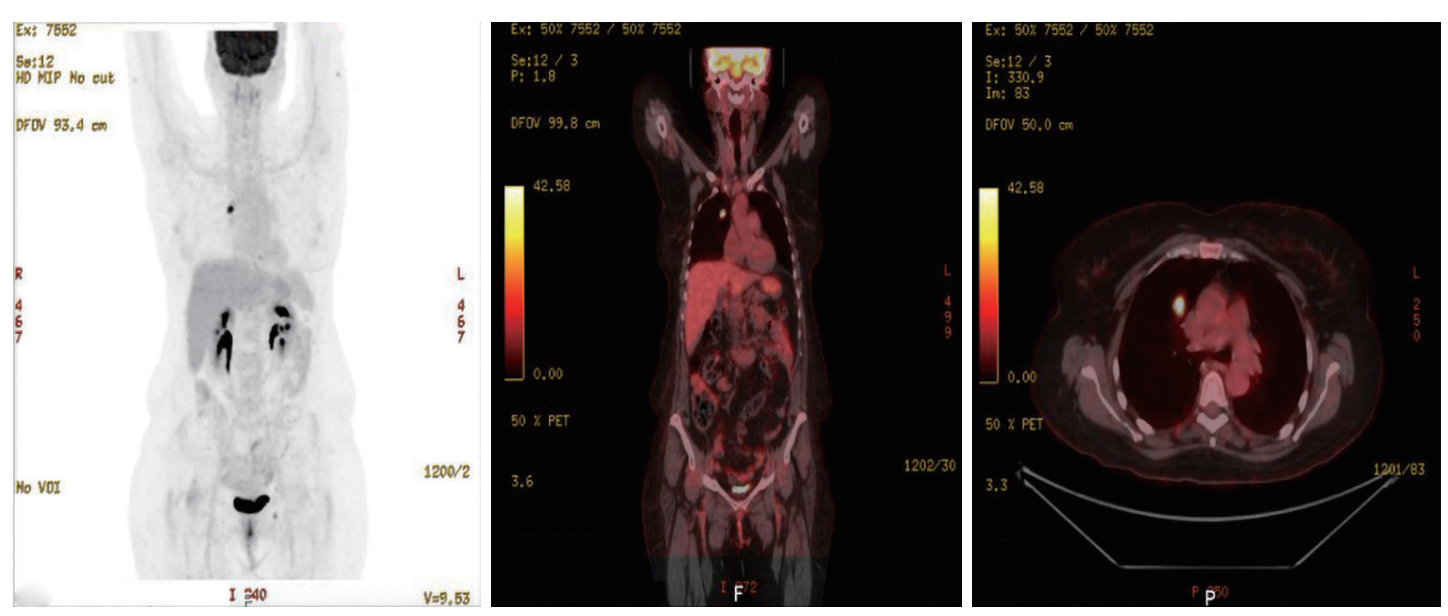

Figure 3 PET-CT showing the metastatic nodule in the right segment 3. PET-CT, positron emission tomography-computed tomography.

and a small Alexis retractor was applied (Video 1). There were no adhesions or pleural deposits, the minor fissure was completely fused and the nodule was not palpable. The exposure of the hilum was optimal and the anterior mediastinal pleura was incised to dissect the upper lobe vein and the truncus anterior using an ultrasound energy device (Harmonic $\left.^{\circledR}, \mathrm{J} \& \mathrm{~J}, \mathrm{USA}\right)$. The segmental venous (V3b and V3a) (Figure 6) and the arterial branch (A3) (Figure 7) for $\mathrm{S} 3$ were dissected. The plane between $\mathrm{V} 1$ and $\mathrm{V} 3 \mathrm{~b}$ and the intersegmental plane along V1 was carefully and broadly dissected. As a noteworthy anatomical variation in this particular case, the central vein ran between B3 and B1 and drained into the right upper lobe vein between $\mathrm{V} 3 \mathrm{~b}$ and $\mathrm{V} 1 \mathrm{a}+\mathrm{b}$. A3 was transected at the level of the anterior trunk, followed by clipping and division of both V3b and V3a. The bronchus (B3) was then dissected and encircled, while the venous branch for the apical segment (V1) was mobilized to facilitate the transection of B3 (Figure 8, Video 2).

Finally, the intersegmental plane between $\mathrm{S} 3$ and both S2 and S1 was demarcated using a hook cautery during the inflation-deflation test, prior to dividing B3. Firstly, the horizontal fissure was transected and the intersegmental planes were stapled from different directions in a V-shape, including the vascular and bronchial stumps (Figure 9), and the specimen was retrieved using an endobag (Covidien ${ }^{\circledR}$, Medtronic, USA). The underwater test was negative for air leak and a fibrin sealant (Tisseel ${ }^{\circledR}$, Baxter, USA) was applied over the hilum (Video 3). A $28 \mathrm{f}$ chest tube was inserted through the same perimammary incision, secured in placed and the utility incision sutured (Figure 10). The estimated blood loss was $50 \mathrm{~mL}$, and the operative time was $90 \mathrm{~min}$. There were no intraoperative or postoperative 


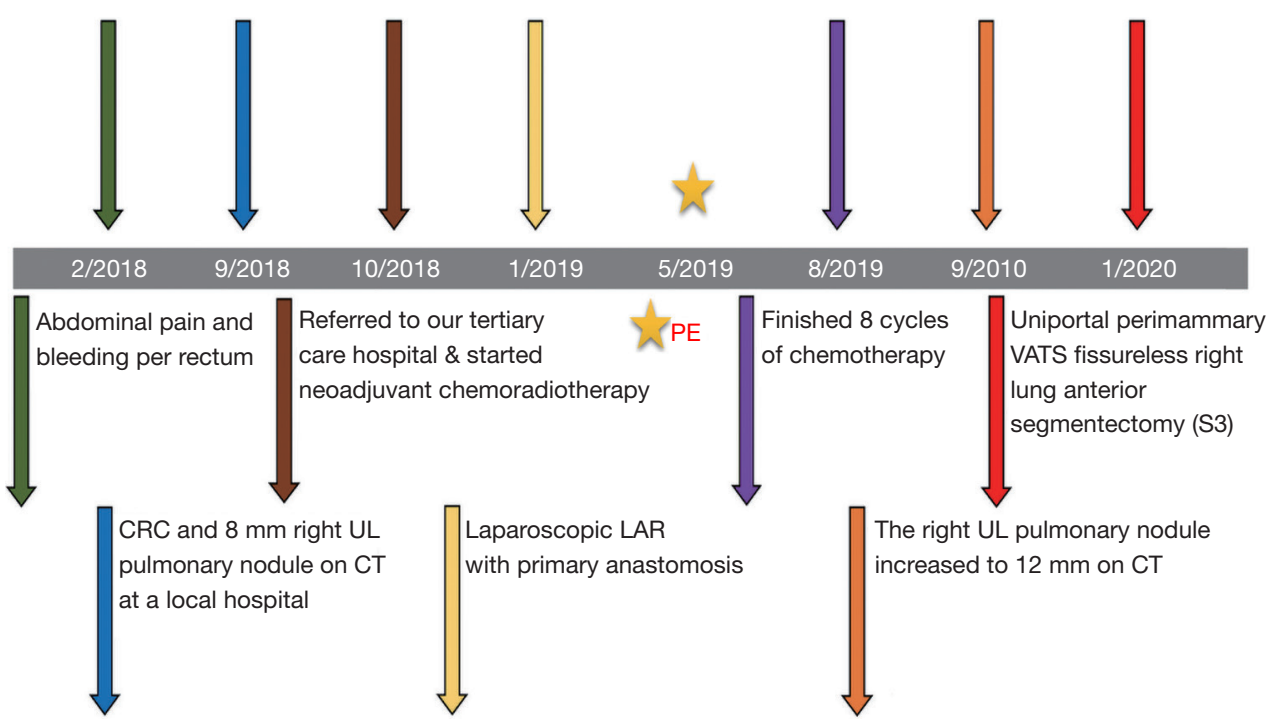

Figure 4 The onset of symptoms, relevant investigations, subsequent chemotherapy course and operative history of the case patient shown for the duration of the study (2018 to 2020). PE, pulmonary embolism; VATS, video assisted thoracic surgery; CRC, colorectal cancer; UL, upper lobe; CT, computed tomography; LAR, low anterior resection.
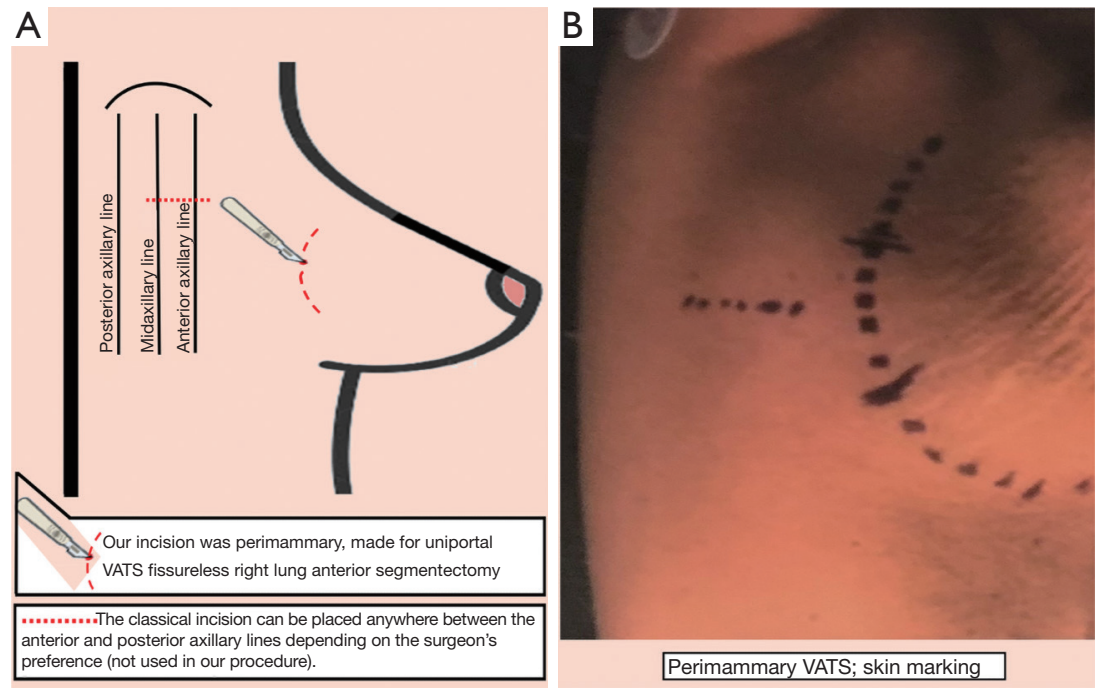

Figure 5 The perimammary approach for uniportal VATS (A) and the skin marking in our patient (B). The fifth intercostal space was aligned with the middle of the utility incision. VATS, video-assisted thoracoscopic surgery.

complications.

The patient tolerated the procedure well. Postoperatively, she received $1 \mathrm{~g}$ intravenous paracetamol every 6 hours and was discharged on the second postoperative day on $650 \mathrm{mg}$ oral paracetamol every 6 hours PRN. However, she did not take the medication at home due to the lack of significant pain. The average postoperative pain (EVA scale) $\pm \mathrm{SD}$ was $0.466 \pm 0.9$ and the long-term cosmetic result was
$2 / 10$, indicating that the patient was "pretty satisfied" (17). The pathology results revealed a $1.5 \mathrm{~cm}$ metastatic adenocarcinoma of colon with a tumor-free resection margin of $1 \mathrm{~cm}$. No signs of recurrence have been observed within 20 months of follow-up.

All procedures performed in this study were in accordance with the ethical standards of the institutional and/or national research committee(s) and with the 


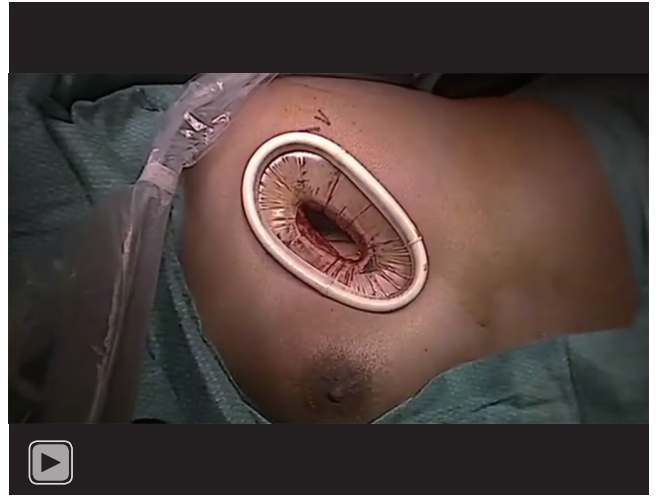

Video 1 Perimammary uniportal approach.

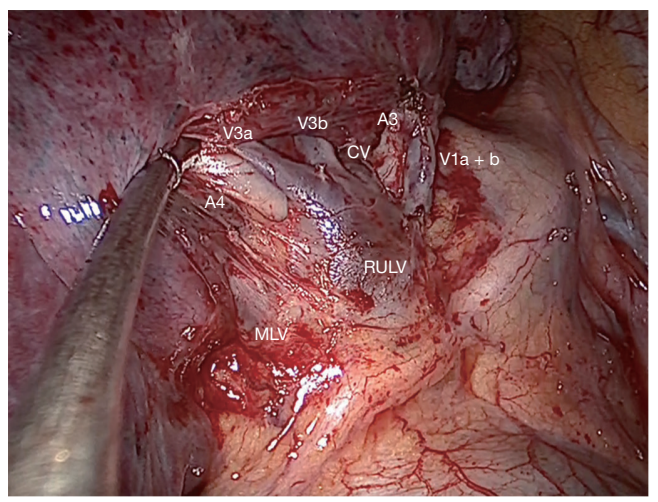

Figure 6 Identification of $\mathrm{V} 3 \mathrm{~b}$ and $\mathrm{V} 3 \mathrm{a}$. RULV, right upper lobe vein; $M L V$, middle lobe vein; $C V$, central vein.

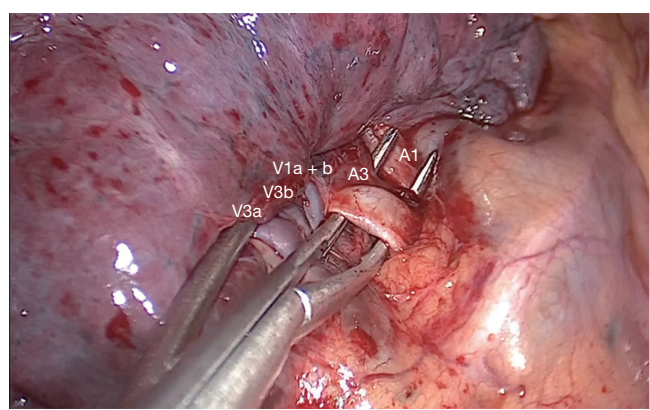

Figure 7 Identification of A3. A1, segmental artery for right S1.

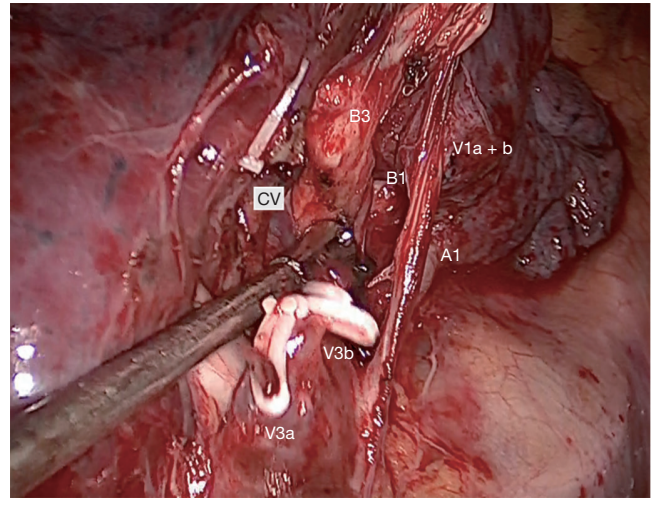

Figure 8 Dissection of B3. CV, central vein; B1, segmental bronchus for right S1; A1, segmental artery for right $\mathrm{S} 1$.

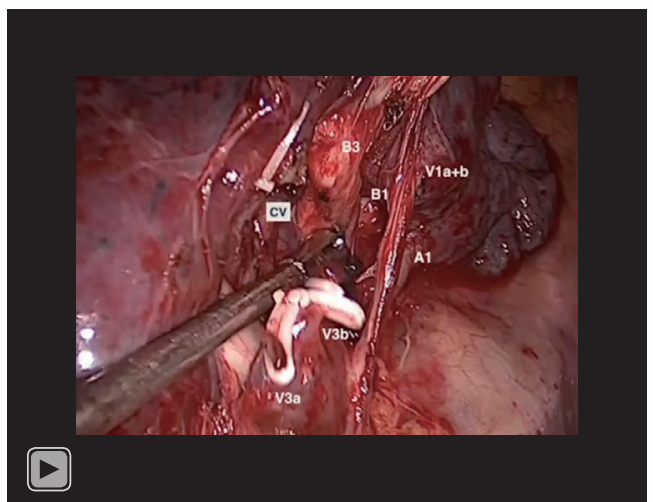

Video 2 Exposure of the hilum and dissection of the upper lobe vein and the truncus anterior using Harmonic ${ }^{\circledR}$ and bimanual instrumentation. First, V3b and V3a and A3 branches were dissected and divided, after which B3 was dissected and V1 was looped to facilitate the transection of B3.

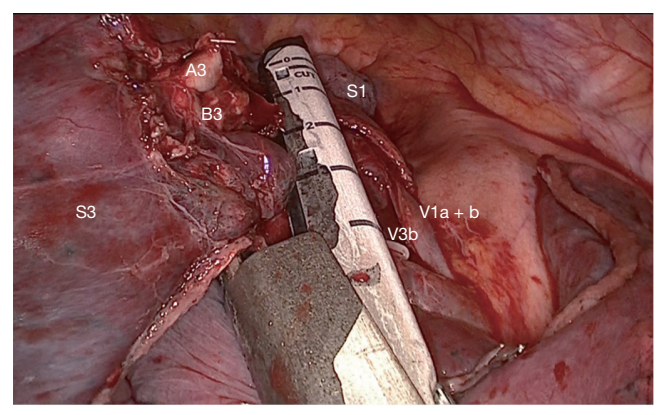

Figure 9 Division of the intersegmental plane including the bronchovascular stumps in the specimen. S1, right segment 1; S3, right segment 3 . 


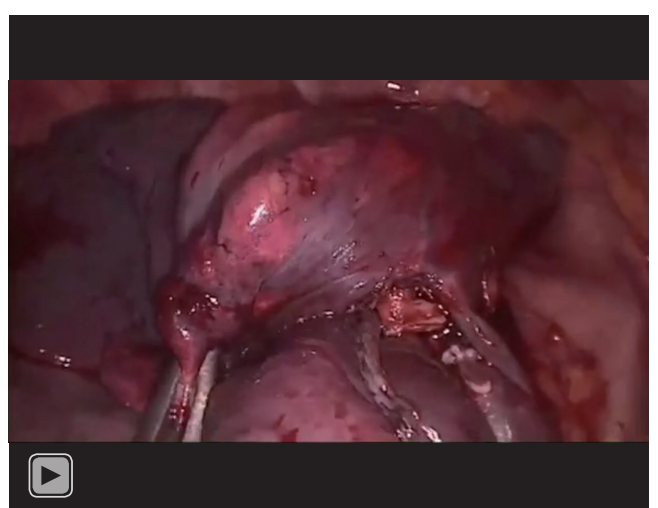

Video 3 Division of the intersegmental planes, including the arterial, venous and bronchial stumps. Retrieval of the specimen, negative underwater test for air leak and Tisseel ${ }^{\circledR}$ application.

Helsinki Declaration (as revised in 2013). The study was reviewed and approved by the Institutional Review Board at King Faisal Specialist Hospital in Riyadh, Saudi Arabia. Written informed consent was obtained from the patient for publication of this case report and accompanying images/ videos. A copy of the written consent is available for review by the editorial office of this journal.

\section{Discussion}

Uniportal VATS is considered a challenging but safe and efficient approach that requires experienced skills, precise instruments and careful preparation, as vision of the surgical field is limited and instrumental handling difficulties can result in catastrophic surgical events in complex surgeries (18). The single-port VATS incision is usually performed through a $3-5 \mathrm{~cm}$ horizontal incision at the 4th or 5 th intercostal space level, providing adequate access to the hilar structures and lymph node stations; however, each incision is made based on the surgeon's preference anywhere between the posterior and anterior axillary lines $(15,19-22)$.

In contrast to the traditional approach, we have presented a novel one for uniportal VATS based on a $3-4 \mathrm{~cm}$ vertical and curved incision performed in the perimammary fold of a female patient. The perimammary utility incision is placed at the level of the selected intercostal space to enter the pleural cavity, in this case the fifth intercostal space, aligning it with the middle of the incision. This approach is placed more anteriorly than the regular utility incision for uniportal VATS, thus providing excellent visualization, improved access to the hilar structures too and a wider intercostal space opening that reduces instrumental collisions and handling difficulties. Furthermore, this approach may decrease postoperative pain, as reported by the patient, and yield a better cosmetic outcome, due to a less-visible scar that is hidden by a brain female patient.

On the other hand, surgical resection is considered an essential approach in managing pulmonary metastases secondary to a CRC (21). Centrally located lung metastasis is an indication for anatomic segmentectomy when the tumor is less than $2 \mathrm{~cm}$ and a wedge resection is not applicable to resect the metastasis with enough free margin while the parenchyma is spared (20). Most of VATS segmentectomies done for lung metastasectomy are considered simple and include the easily excised segments, such as the basilar, superior and lingular segments. However, complex segmentectomies require more experience since the main difficulty is based on the distal dissection of hilar structures and the segmental plane division. Surgeons must also contend with anatomical variations and incomplete fissures, which increase the technical difficulty of this particular approach (20).

Hernandez-Arenas et al. have summarized uniportal VATS right S3 segmentectomy procedure to 6 surgical steps, placing the utility incision at the 4th intercostal space. The first step is to expose the anterior mediastinal pleura and identify the mediastinal trunk and the upper vein to start dissecting and dividing A3 first, then V3, and finally, B3 to end completing the intersegmental fissure created after the insufflation test (19).

Lutz et al. reported a fissureless uniportal VATS right upper lobe S3. The horizontal fissure was absent in that case, but it was transected to allow better visual access to S3 bronchovascular pedicle using a tunneling technique, thus allowing dissection of the pulmonary artery in the oblique fissure. Next, the surgical team identified the upper lobe vein and its posterior vein branch (V2), followed by the middle lobe artery (A4) and the main pulmonary artery, finally opening its vascular sheath to allow for smooth tunneling. The instruments were passed along V2-venous branch. Lastly, to maximise exposure of the bronchovascular pedicle of S3, they passed a silastic sling and used an endostapler to divide the parenchyma. This allowed the team to continue with the dissection and transection of $\mathrm{V} 3 \mathrm{~b}$ and V3a, A3 and B3 to finalize stapling the parenchyma from different directions to diminish the tension on the suture line. The operation time was 150 minutes and the patient was discharged on the third postoperative day (21). 

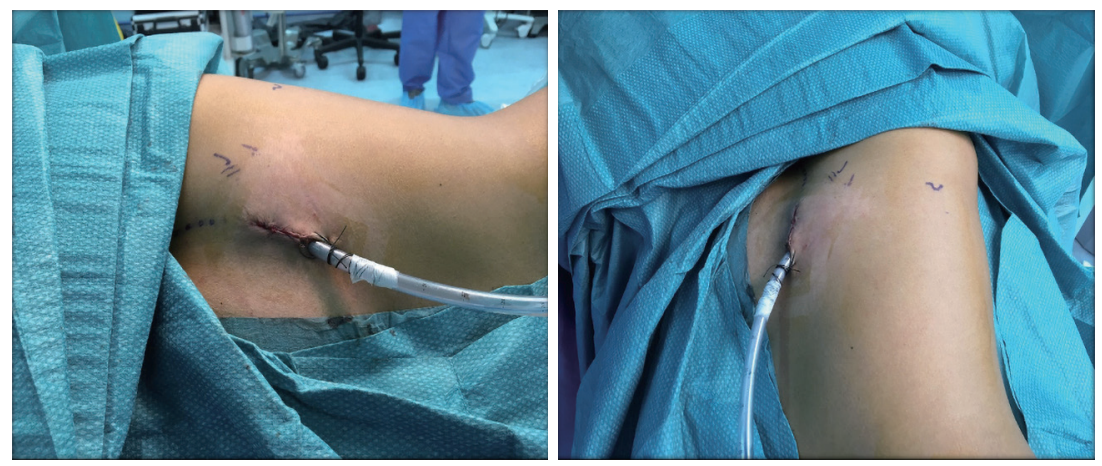

Figure 10 Final result of the perimammary approach performed on another patient to show the utility incision in a neutral surgical position. The chest tube is secured in placed in the lower corner of the utility incision.

In a later report, the authors mentioned that the average operation time for 15 uniportal VATS right segmentectomy S3 done by them following the steps described above by Lutz was 150 minutes (range, 100-252 minutes), and in particular, the patient was discharged on the fourth postoperative day (22).

In our case, the exposure achieved through the perimammary approach and the fifth intercostal space was optimal and reduced instrumental collisions and handling difficulties. The sequence of surgical steps followed in our fisureless segmentectomy was similar to the one reported by Hernandez-Arenas et al. (19), with the exception that we started by dissecting $\mathrm{S} 3$ veins and then $\mathrm{A} 3$. A careful broad dissection of the planes between $\mathrm{V} 3 \mathrm{~b}$ and $\mathrm{V} 1$ and the intersegmental plane along V1 facilitated the identification of the abnormal central vein and the dissection and transection of A3 and mainly B3, which may help to reduce the surgical time without associated increase to the risk of postoperative air leak.

As we performed a fissureless technique, we did not transect the horizontal fissure to dissect the pulmonary artery in the fissure and, therefore, it was not necessary to identify V2 or A4 or open the pulmonary artery sheet to create a tunnel, or even dissect B3 posteriorly in the fissure. This allowed us to perform a fissureless S3 segmentectomy in a shorter time and facilitated patient discharge on the second postoperative day due to the absence of air leak and the low pain observed. The division of the intersegmental plane in a V-shape from different directions starting by the separation of S3 from S2 and then from S1 is more anatomical and decreases the tension on the suture line, which consequently reduces the risk of postoperative air leaks. In conclusion, this novel perimammary uniportal approach allowed us to safely perform a complex segmentectomy for lung metastasectomy with adequate exposure of the hilum, minimal postoperative pain, a shortened hospital stay, sufficient free margin, and an excellent cosmetic result that provided high patient satisfaction. Further studies are required to prove the benefits of the perimammary approach.

\section{Acknowledgments}

We would like to thank Dr. Brooke Brisbine and Ms. Cristina Riera López for their technical support.

Funding: None.

\section{Footnote}

Provenance and Peer Review: This article was commissioned by the Guest Editor (Michel Gonzalez) for the series "VATS Segmentectomy" published in fournal of Visualized Surgery. The article has undergone external peer review.

Reporting Checklist: The authors have completed the CARE reporting checklist. Available at https://jovs.amegroups. com/article/view/10.21037/jovs-21-39/rc

Conflicts of Interest: All authors have completed the ICMJE uniform disclosure form (available at https://jovs. amegroups.com/article/view/10.21037/jovs-21-39/coif). The series "VATS Segmentectomy" was commissioned by the editorial office without any funding or sponsorship. DGR serves as the unpaid Associate Editor-in-Chief of Fournal of Visualized Surgery from October 2020 to September 2022. The authors have no other conflicts of 
interest to declare.

Ethical Statement: The authors are accountable for all aspects of the work in ensuring that questions related to the accuracy or integrity of any part of the work are appropriately investigated and resolved. All procedures performed in this study were in accordance with the ethical standards of the institutional and/or national research committee(s) and with the Helsinki Declaration (as revised in 2013). The study was reviewed and approved by the Institutional Review Board at King Faisal Specialist Hospital in Riyadh, Saudi Arabia. Written informed consent was obtained from the patient for publication of this case report and accompanying images/videos. A copy of the written consent is available for review by the editorial office of this journal.

Open Access Statement: This is an Open Access article distributed in accordance with the Creative Commons Attribution-NonCommercial-NoDerivs 4.0 International License (CC BY-NC-ND 4.0), which permits the noncommercial replication and distribution of the article with the strict proviso that no changes or edits are made and the original work is properly cited (including links to both the formal publication through the relevant DOI and the license). See: https://creativecommons.org/licenses/by-nc-nd/4.0/.

\section{References}

1. August DA, Ottow RT, Sugarbaker PH. Clinical perspective of human colorectal cancer metastasis. Cancer Metastasis Rev 1984;3:303-24.

2. Seymour MT, Stenning SP, Cassidy J. Attitudes and practice in the management of metastatic colorectal cancer in Britain. Clin Oncol (R Coll Radiol) 1997;9:248-51.

3. Penna C, Nordlinger B. Colorectal metastasis (liver and lung). Surg Clin North Am 2002;82:1075-90, x-xi.

4. Inoue $M$, Ohta $M$, Iuchi $K$, et al. Benefits of surgery for patients with pulmonary metastases from colorectal carcinoma. Ann Thorac Surg 2004;78:238-44.

5. Han KN, Kim HK, Lee HJ, et al. Single-port videoassisted thoracoscopic pulmonary segmentectomy: A report on 30 cases. Eur J Cardiothorac Surg 2016;49 Suppl $1: 142-7$.

6. Rocco G, Martin-Ucar A, Passera E. Uniportal VATS wedge pulmonary resections. Ann Thorac Surg 2004;77:726-8.

7. Gonzalez D, Paradela M, Garcia J, et al. Single-port video- assisted thoracoscopic lobectomy. Interact Cardiovasc Thorac Surg 2011;12:514-5.

8. Gonzalez-Rivas D, Fernandez R, Fieira E, et al. Uniportal video-assisted thoracoscopic bronchial sleeve lobectomy: First report. J Thorac Cardiovasc Surg 2013;145:1676-7.

9. Zhu Y, Xu GB, Lei CG, et al. Thoracic surgery: Singleport video-assisted thoracoscopic lobectomy. Ann Transl Med. 2015;3:143.

10. Gonzalez-Rivas D, de la Torre M, Fernandez R, et al. Single-port video-assisted thoracoscopic left upper lobectomy. Interact Cardiovasc Thorac Surg 2011;13:539-41.

11. Mier JM, Chavarin A, Izquierdo-Vidal C, et al. A prospective study comparing three-port video-assisted thoracoscopy with the single-incision laparoscopic surgery (SILS) port and instruments for the video thoracoscopic approach: A pilot study. Surg Endosc 2013;27:2557-60.

12. Ye Z, Zhang B, Chen Y, et al. Comparison of single utility port video-assisted thoracoscopic surgery (VATS) and three-port VATS for non-small cell lung cancer. Oncol Lett 2019;18:1311-7.

13. Rocco G, Martucci N, La Manna C, et al. Ten-year experience on 644 patients undergoing single-port (Uniportal) video-assisted thoracoscopic surgery. Ann Thorac Surg 2013;96:434-8.

14. Wang $\mathrm{L}$, Liu $\mathrm{D}, \mathrm{Lu} \mathrm{J}$, et al. The feasibility and advantage of uniportal video-assisted thoracoscopic surgery (VATS) in pulmonary lobectomy. BMC Cancer 2017;17:75.

15. Gonzalez-Rivas D. Single incision video-assisted thoracoscopic anatomic segmentectomy. Ann Cardiothorac Surg 2014;3:204-7.

16. CARE Checklist - CARE Case Report Guidelines. Available online: https://www.care-statement.org/checklist

17. POSAS Patient scale The Patient and Observer Scar Assessment Scale v 2.0/EN. Available online: https://www. posas.nl/downloads/

18. Flores RM, Ihekweazu U, Dycoco J, et al. Video-assisted thoracoscopic surgery (VATS) lobectomy: catastrophic intraoperative complications. J Thorac Cardiovasc Surg 2011;142:1412-7.

19. Hernandez-Arenas LA, Purmessur RD, Gonzalez-Rivas D. Uniportal video-assisted thoracoscopic segmentectomy. J Thorac Dis 2018;10:S1205-14.

20. Gonzalez-Rivas D, Fieira E, Mendez L, et al. Single-port video-assisted thoracoscopic anatomic segmentectomy and right upper lobectomy. Eur J Cardiothorac Surg 2012;42:e169-71. 
21. Lutz JA, Dorn P, Schmid RA, et al. Upper lobe anterior segment (S3): technique of fissureless uniportal VATS segmentectomy. J Thorac Dis 2018;10:3797-9.

doi: $10.21037 /$ jovs-21-39

Cite this article as: Santana-Rodriguez N, Alhayaza R, AlShammari A, Alhayaza RM, Ahmed A, Alashgar O, GonzálezRivas D. Perimammary uniportal vats fissureless right anterior segmentectomy for lung metastasectomy: a case report. J Vis Surg 2023;9:18.
22. Gioutsos K, Lutz JA. Tips and tricks in uniportal anterior segmentectomy (S3) of the right upper lobe. VideoAssisted Thorac Surg 2020;5:15. 